\title{
Ethnic Differences in Breastfeeding Initiation and Duration among Mothers Attending Primary Healthcare Clinics in Paramaribo, Suriname \\ AE Getrouw $^{1}$, AD Hindori-Mohangoo ${ }^{2,3}$, W Zijlmans ${ }^{4,5}$, DRA Mans ${ }^{4,6}$
}

\begin{abstract}
Objective: To determine the association between maternal ethnicity and breastfeeding initiation (child ever fed breastmilk) and duration (child breastfed for at least 6 months) in Suriname.

Methods: Mothers of 6-11 months old infants who attended the Regional Health Service clinics in Paramaribo for routine well-baby care services were invited to participate during a period of eight weeks. Information about breastfeeding initiation and duration, maternal and child characteristics were obtained using an interviewer-administered questionnaire. Logistic regression models were applied to examine independent associations with never breastfeeding and breastfeeding less than 6 months.

Results: Maroon mothers had the highest proportions of ever breastfeeding (99\%) and breastfeeding for at least 6 months (77\%), while Hindustani mothers had the lowest $(90 \%$ and $27 \%$, respectively). Javanese mothers had the second highest proportion of ever breastfeeding $(98 \%)$, but the second lowest proportion of breastfeeding for at least 6 months $(50 \%)$. Compared with Maroon mothers, Hindustani, Creole and mothers with mixed ethnicity had significantly higher odds of never breastfeeding, while Hindustani, Javanese and Creole mothers had significantly higher odds for breastfeeding less than 6 months.

Conclusion: Wide maternal ethnic variations in breastfeeding initiation and duration exist in Suriname. Other maternal or child factors do not account for the observed variations. These may reflect cultural norms and should be further explored.
\end{abstract}

Keywords: Breastfeeding, ethnic differences, Suriname

From: ${ }^{1}$ Bureau of Public Health, Ministry of Health Suriname, Paramaribo, Suriname. ${ }^{2}$ Department of Public Health, Faculty of Medical Sciences, Anton de Kom University of Suriname, Paramaribo, Suriname. ${ }^{3}$ Department of Child Health, Netherlands Organization for Applied Scientific Research, TNO Healthy Living, Leiden, The Netherlands. ${ }^{4}$ Scientific Research Center Suriname, Academic Hospital Paramaribo, Paramaribo, Suriname. ${ }^{5}$ Kids Clinic\& Department of Pediatrics, Diakonessenhuis, Paramaribo, Suriname. ${ }^{6}$ Department of Pharmacology, Faculty of Medical Sciences, Anton de Kom University of Suriname, Paramaribo, Suriname.

Correspondence: Ms A Getrouw, Bureau of Public Health, Rode Kruislaan 22, P.O.Box 767

Paramaribo, Suriname. Fax: + (597) 491452, e-mail: bognutrition@gmail.com 


\section{INTRODUCTION}

Breastfeeding provides short- and long-term health benefits for both the lactating mother and her child (1-2) which increase with increasing degree and duration of breastfeeding (1). For instance, exclusive breastfeeding during the first six months conveys lower risk of gastrointestinal infection for the baby and delayed return of menstrual periods (3). For these reasons, international organizations such as the United Nations Children's Fund (UNICEF) and the World Health Organization (WHO) recommend that infants are exclusively breastfed during the first six months of life and that breastfeeding should be continued for at least two years (4). At the time of this study, the Bureau of Public Health (Bureau voor Openbare Gezondheidszorg), under the Ministry of Health, recommended exclusive breastfeeding during the first 4 to 6 months of life, and continued breastfeeding for 1 to 2 years (5).

The Republic of Suriname is located on the north-eastern coast of South America and has a multi-ethnic population, mainly of African, East-Indian and Indonesian ancestry. For the time period under study, the five main ethnic groups were: Hindustanis, Maroons, Creoles, Javanese, and individuals from mixed ethnicity (6). Several studies in Western populations have shown that breastfeeding practices vary between ethnic groups (7-9). A British study reported that white women are less likely to start breastfeeding compared with most Asian and Black ethnic groups (8).

In contrast, a study conducted in the USA found that black women were less likely to breastfeed than non-black women and preferred to bottle-feed (7). This raises the possibility that maternal ethnicity may play a role in breastfeeding behavior. Despite these findings, of the few studies that have assessed breastfeeding practices in Suriname, only one (10) reported ethnic-specific results with respect to breastfeeding. That study found that the proportion of children ever breastfed was lower among households headed by Hindustani, Creole, Javanese or mixed individuals compared to households headed by Maroons. And the median duration 
of any breastfeeding was 10.8 and 6.2 months in households led by a Maroon or a Creole, but only 3.8 to 5.2 months in those headed by a Hindustani, Javanese, or individual of mixed ethnic background (10). However, as the ethnic background of the head of household may differ from that of the mother who actually feeds the child, it may be that the association between the household head's ethnic background and breastfeeding differs from the association with the mother's ethnicity. Therefore, the aim of this study was to determine whether there are differences in breastfeeding practices between mothers of diverse ethnic backgrounds attending Regional Health Service (Regionale Gezondheidsdienst - RGD) clinics in Paramaribo, and whether these differences are associated with maternal or infant characteristics.

\section{METHODS}

\section{Design and participants}

This cross-sectional study was carried out in Paramaribo, the capital of Suriname. The study took place from June 15 to August 10, 2011 and mothers and caregivers who attended the well-baby care services of all 12 RGD clinics in Paramaribo were invited to participate. RGD is a government-funded health organization that offers a range of primary healthcare services to individuals in the coastal area of Suriname. Participants were eligible if they were the primary caregiver of the infant, had an infant aged 6 to 11 months, were able to understand and speak Dutch or the local language, did not have an adopted baby, and had a baby without health problems that would interfere with breastfeeding. 


\section{Data collection}

Respondents were selected by staff members of the clinics and face-to-face interviewed in a consulting room or in a quiet area away from other mothers. The questions were adapted from existing questionnaires (11-13) and provided information on socio-demographic characteristics of mothers and infants, infant's birth weight, preterm birth, breastfeeding initiation and duration. Information on birth weight and preterm birth was cross-checked against maternal clinical records. The questionnaire was first used in a pilot study of ten mothers in a clinic other than that of the RGD but with a comparable clientele.

\section{Definitions}

Breastfeeding initiation was defined as the proportion of mothers who ever tried to breastfeed after birth ('ever breastfeeding'), and was assessed by the question "Has (name of infant) ever been breastfed or fed breastmilk?'. The duration of 'any' breastfeeding referred to the proportion of mothers who initiated breastfeeding and continued to feed any breastmilk for six months or more (thus even if they also gave other foods and formula or drinks). Information was collected by asking "How old was (name of infant) when you stopped breastfeeding?" For mothers who were still breastfeeding at the time of the interview, duration was set at the age of infant at the time of the interview.

\section{Study variables}

The outcome variables were whether the child was ever breastfed (yes vs. no) and whether the child was breastfed for at least 6 months (yes vs. no). Maternal ethnicity, the main independent variable, was defined according to survey responses and categorized to Suriname Census division of ethnic groups as Creole, Hindustani, Javanese, Maroon and mixed ethnicity. The remaining smaller groups mainly Amerindians and Chinese, were classified as 
"other ethnicity". Variables that were included in the analysis as potential confounders on the relationship between maternal ethnic background and breastfeeding were: maternal age at the time of the interview ( $<20$ years, $20-24,25-29,30-34$ and $35+$ years $)$, mother's educational level (no education, primary education, lower secondary education, higher secondary education or more), gender of infant, low birth weight ( $<2500$ vs. $2500+$ grams), preterm birth (<37.0 vs. 37.0+ weeks) and region of RGD clinic (north-east vs. south-west, classification was based on the official administrative division of Paramaribo).

\section{Statistical analysis}

Descriptive statistics for the study population were presented by maternal ethnicity. Differences in proportions of maternal and infant characteristics by each outcome variable were tested using the $\mathrm{X}^{2}$-test. Multivariate logistic regression models were applied to assess independent associations between maternal ethnicity and each outcome variable, adjusted for maternal and infant characteristics. All analyses were performed using the Statistical Package for the Social Sciences (SPSS) version 22.0 for Windows (SPSS Inc., Chicago, Illinois, USA).

\section{Ethical considerations}

Ethical and administrative approval was obtained from the Ministry of Health in Suriname and the director of RGD. Although not required by the Ministry of Health, verbal consent was obtained from all participants. 


\section{RESULTS}

Of the 603 participants who were selected, 578 completed the interview (95.8\%). Of these mothers and caregivers, only those who were the infants' biological mother were included. Participants who were not the natural mother $(n=32)$ were excluded because it was likely that their information on breastfeeding initiation and duration would be inaccurate. Due to small numbers, participants with an ethnicity other than Hindustani, Maroon, Creole, Javanese, or mixed ( $n=16)$, with missing data on ethnic background $(n=4)$ and with an infant that did not meet the age criteria $(n=4)$ were also excluded. Eventually, the sample for analysis included 522 mother-infant pairs.

Of the 522 mothers, $27 \%$ was Creole, $22 \%$ Maroon, $22 \%$ had a mixed ethnicity, $21 \%$ was Hindustani, and 9\% Javanese (Table 1). The majority of the mothers (63.5\%) was 20 to 29 years of age, and most (38.5\%) had completed a lower secondary education. About 50\% of the infants was male, $5.7 \%$ had a low birth weight, and $6.5 \%$ was born preterm. Comparison of maternal and infant characteristics among ethnic groups showed that educational level $(\mathrm{p}<0.001)$ and region of RGD clinic $(\mathrm{p}=0.033)$ displayed a statistically significant association with maternal ethnicity. Low birth weight $(\mathrm{p}=0.067)$ had a marginal association with maternal ethnicity.

Table 2 presents bivariate analyses for breastfeeding initiation and duration. Maroon and Javanese mothers most often initiated breastfeeding (99.1 and 97.8\%, respectively), followed by mothers with a mixed $(93.1 \%)$ and Creole $(91.5 \%)$ background. Hindustani mothers had the lowest proportion $(89.7 \%)$. Maternal ethnicity $(\mathrm{p}=0.027)$ and low birth weight $(\mathrm{p}=0.034)$ were significantly associated with ever breastfeeding. Low birth weight infants were less often ever breastfed than normal birth weight babies (83.3\% versus $94.3 \%)$. Infant gender and preterm birth were also associated with ever breastfeeding, but this was of borderline significance ( $\mathrm{p}$-values of 0.053 and 0.055 , respectively). 
Of the mothers who initiated breastfeeding, 59.5\% continued breastfeeding for at least 6 months (range 27.1\% Hindustani mothers -76.8\% Maroon mothers) (Table 2). The proportions observed among mixed, Creole, and Javanese mothers were 73, 61, and 50\%, respectively. Maternal ethnicity was significantly associated with breastfeeding duration $(p<0.001)$. Region of RGD clinic $(p=0.066)$ was marginally associated.

After adjustment for low birth weight, the odds ratios for never breastfeeding for Hindustani, Creole, and mixed ethnicity remained statistically significant, although their magnitude decreased by 5 to $12 \%$ (Table 3). Compared with Maroon mothers, Hindustani, Creole, and mothers with mixed ethnicity had significantly higher odds of never breastfeeding, respectively 11.7, 9.3 and 7.9 times higher. Adjustment for region of RGD clinic had no effect on the odds ratios for breastfeeding less than 6 months across all ethnic groups: Hindustani, Javanese, and Creole mothers had significantly higher odds of breastfeeding less than 6 months compared with Maroon mothers, respectively 9.6, 3.1 and 2.2. In addition, mothers visiting RGD clinics in north-east Paramaribo had $60 \%$ higher odds of breastfeeding less than 6 months compared with mothers visiting south-west clinics.

\section{DISCUSSION}

This study on breastfeeding practices among mothers visiting RGD clinics for routine wellbaby care in Paramaribo showed that breastfeeding initiation and duration differed by maternal ethnicity. Maroon mothers had the highest proportions of ever breastfeeding and breastfeeding for at least 6 months, while Hindustani mothers had the lowest. Javanese mothers had the second highest proportion of ever breastfeeding, but the second lowest proportion of breastfeeding for at least 6 months. These associations between maternal 
ethnicity and breastfeeding remained statistically significant after adjustment for maternal and infant characteristics.

The high proportions of breastfeeding initiation across different ethnic groups are in line with national breastfeeding data (10). Given the short median duration rates of breastfeeding reported previously (10), it is also not surprising that only $60 \%$ of mothers in this sample continued breastfeeding for at least 6 months. Furthermore, the finding that Maroon mothers stood out as having higher proportions of both breastfeeding initiation and duration is consistent with the most recent MICS survey, although ethnicity in the MICS study was defined based on head of the household (10). Other (international) studies have also reported ethnic differences in breastfeeding practices among different ethnic groups (79). Our finding that ethnic differences in breastfeeding practices remained statistically significant after correction for maternal and infant characteristics is consistent with these studies (7-9).

Cultural background has been suggested as a possible explanation for the differences in breastfeeding patterns between ethnic groups (7-9). A study from The Netherlands pointed out that the high breastfeeding initiation rates among Mediterranean - mostly Muslim women may be related to the recommendation in the Koran to breastfeed children for two entire years (9). The ethnic differences in breastfeeding practices observed in this study may also reflect cultural influences. Among Maroons, for instance, breastfeeding may be considered the norm as it is in many West-African countries evident in the high rates of partial and continued breastfeeding (14). Similarly, certain unidentified cultures and traditions for withholding colostrum and giving prelacteal feeds in various parts of India (15, 16) may account for the relatively low score of Hindustani mothers regarding breastfeeding practices. Future studies should therefore focus on women's attitude, social-cultural environment, and self-efficacy towards breastfeeding practices in Suriname. Additional 
research is also needed to clarify the observation that region of the RGD clinic in Paramaribo was independently associated with breastfeeding duration, as this may reflect differences in breastfeeding support among clinics or whether this is an association with SES (socioeconomic status of the region).

This study has a few limitations. Firstly, results are based on a cross-sectional study design which limits causal associations. Secondly, results are based on a non-probability sample and should therefore be cautiously generalized to all mothers visiting the RGD clinics in Paramaribo. Finally, as mentioned earlier, information on other determinants of breastfeeding practices, such as maternal employment status, household income, mode of delivery, having a support system and lifestyle related characteristics (7-9), was not available in this study. Therefore, we cannot rule out the possibility that unmeasured factors accounted for the findings seen in this study. Although data on breastfeeding practices are based on maternal reports, several studies have shown that maternal reporting of breastfeeding practices are accurate when recall is within 3 years $(17,18)$. The possibility for recall bias is therefore negligible or small.

\section{CONCLUSION}

This study revealed substantial differences in breastfeeding initiation and duration by maternal ethnicity in Paramaribo which have not been reported previously. The maternal and infant factors examined did not account for the observed differences, suggesting that cultural factors may contribute to these differences. However, more research is needed to understand the observed differences in breastfeeding practices in Suriname, to ensure the development of effective interventions to improve breastfeeding practices, and reduce disparities between ethnic groups. 


\section{ACKNOWLEDGMENTS}

The authors would like to thank all the women who participated in the study and acknowledge the cooperation of the staff from the RGD clinics. The Bureau of Public Health is acknowledged for providing financial support to carry out this study.

\section{AUTHORS' NOTE}

AE Getrouw conceived and designed the study, supervised collection of data, contributed to the interpretation of the data, wrote the manuscript and approved the final version. $\mathrm{AD}$ Hindori-Mohangoo conducted statistical analysis, collaborated in the interpretation of the data and revision of the manuscript and approved the final version. W. Zijlmans participated in the interpretation of the data and revision of the manuscript, and approved the final version. DRA Mans provided expertise in the design, participated in the interpretation of the data, critically revised the manuscript and approved the final version. 


\section{REFERENCES}

1. León-Cava N, Lutter C, Ross J, Martin L. Quantifying the benefits of breastfeeding: a summary of the evidence [Internet]. Washington (DC): PAHO; 2002 Jun [cited 2011 Jan 5]. Available from: http://www.linkagesproject.org/media/publications/Technical\%20Reports/BOB.pdf

2. Horta BL, Bahl R, Martines JC, Victor CG. Evidence on the long-term effects of breastfeeding: systematic reviews and meta-analyses [Internet]. Geneva, Switzerland: World Health Organization; 2007 [cited 2011 Jan 19]. Available from: http://whqlibdoc.who.int/publications/2007/9789241595230_eng.pdf

3. World Health Organization. The optimal duration of exclusive breastfeeding: report of an expert consultation. Geneva, Switzerland: World Health Organization; 2001.

4. World Health Organization/United Nations Children's Fund. The Global Strategy for Infant and Young Child Feeding. Geneva, Switzerland: World Health Organization; 2003.

5. Bureau voor Openbare Gezondheidszorg. Baby- en peuterboek. Paramaribo, Suriname: BOG; 2001.

6. Algemeen Bureau voor de Statistiek in Suriname. Zevende algemene volks- en woningtelling in Suriname. Distrikt resultaten. Demografische en sociale karakteristieken. Suriname in cijfers no 224 - 2006/06. Paramaribo, Suriname: Algemeen Bureau voor de Statistiek/Censuskantoor; 2006.

7. Forste R, Jessica Weiss J, Lippincott E. Decision to breastfeed in the United States: Does race matter? Pediatrics. 2001; 108: 291-6.

8. Kelly YJ, Watt RG, Nazroo JY. Racial/Ethnic differences in breastfeeding initiation and continuation in the United Kingdom and comparison with findings in the United States. Pediatrics 2006; 118: e1428-35. 
9. van Rossem L, Vogel I, Steegers EAP, Moll HA, Jaddoe VWV, Hofman A, et al. Breastfeeding patterns among ethnic minorities: the Generation $\mathrm{R}$ Study. $\mathrm{J}$ Epidemiol Community Health [Internet]. 2010 [cited 2012 Jan 16]; 64: 1080-5. Available from:

http://jech.bmj.com/content/64/12/1080.full.pdf

10. Ministry of Social Affairs and Housing; General Bureau of Statistics. Suriname multiple indicator cluster survey 2010, Final report. Paramaribo, Suriname; 2012.

11. Bolling K, Grant C, Hamlyn B, Thornton A. Infant feeding survey 2005. A survey conducted on behalf of the Information Centre for health and social care and the UK Health Departments by BMRB Social Research [Internet]. [place unknown]:The Information Centre; 2007. [cited 2011 Feb 1]. Available from: http://www.ic.nhs.uk/webfiles/publications/ifs06/2005Infant Feeding Survey (final version).pdf

12. Centers for Disease Control and Prevention. NIS Survey Methods [Internet]. Atlanta (GA): $\quad \mathrm{CDC} ; \quad$ [cited 2011 Feb 1]. Available from: http://www.cdc.gov/breastfeeding/data/nis_data/survey_methods.htm

13. World Health Organization. Indicators for assessing infant and young child feeding practices part 2: measurement. Geneva, Switzerland: WHO Press; 2010.

14. Lauer JA, Betrán AP, Victora CG, de Onís M, Barros AJD. Breastfeeding patterns and exposure to suboptimal breastfeeding among children in developing countries: review and analysis of nationally representative surveys. BMC Medicine [Internet]. 2004 [cited 2015 Aug 15]; 2:26. Available from: http://www.biomedcentral.com/1741-7015/2/26

15. Bandyopadhyay M: Impact of ritual pollution on lactation and breastfeeding practices in rural West Bengal, India. Int Breastfeed J [Internet]. 2009 [cited 2015 Aug 15]; 4:2. 
Available from: http://www.internationalbreastfeedingjournal.com/content/pdf/17464358-4-2.pdf

16. Laroia N, Sharma D: The religious and cultural basis for breastfeeding practices among the Hindus. Breastfeed Med 2006; 1: 94-8.

17. Li R, Scanlon KS, Serdula MK. The validity and reliability of maternal recall of breastfeeding practice. Nutr Rev 2005; 63:103-10.

18. Cupul-Uicab LA, Gladen BC, Hernández-Avila M, Longnecker MP. Reliability of reported breastfeeding duration among reproductive-aged women from Mexico. Matern Child Nutr [Internet]. 2009 [cited 2011 Mar 8]; 5(2): 125-37. Available from: http://www.ncbi.nlm.nih.gov/pmc/articles/PMC2923918/pdf/nihms103918.pdf 
Table 1: General characteristics of the study population according to maternal ethnicity $(\mathrm{n}=522)$

\begin{tabular}{|c|c|c|c|c|c|c|c|}
\hline Characteristic & $\begin{array}{c}\text { Total } \\
(\mathrm{n}=522)\end{array}$ & $\begin{array}{c}\text { Creole } \\
(n=141)\end{array}$ & $\begin{array}{c}\text { Hindustani } \\
(n=107)\end{array}$ & $\begin{array}{c}\text { Javanese } \\
(n=45)\end{array}$ & $\begin{array}{c}\text { Maroon } \\
(n=113) \\
\end{array}$ & $\begin{array}{c}\text { Mixed } \\
(\mathrm{n}=116)\end{array}$ & p-value \\
\hline \multicolumn{8}{|l|}{ Ever breastfeeding } \\
\hline Yes & $93.7 \%$ & $91.5 \%$ & $89.7 \%$ & $97.8 \%$ & $99.1 \%$ & $93.1 \%$ & 0.027 \\
\hline No & $6.3 \%$ & $8.5 \%$ & $10.3 \%$ & $2.2 \%$ & $0.9 \%$ & $6.9 \%$ & \\
\hline Breastfeeding duration (months) & & & & & & & $<0.001$ \\
\hline$<6$ & $40.5 \%$ & $39.4 \%$ & $72.9 \%$ & $50.0 \%$ & $23.2 \%$ & $26.9 \%$ & \\
\hline$\geq 6$ & $59.5 \%$ & $60.6 \%$ & $27.1 \%$ & $50.0 \%$ & $76.8 \%$ & $73.1 \%$ & \\
\hline Median & 6.0 & 6.0 & 3.5 & 5.5 & 7.0 & 6.0 & \\
\hline$[\mathrm{IQR}]$ & {$[3.0-8.0]$} & {$[3.0-8.0]$} & {$[2.0-6.0]$} & {$[2.0-7.0]$} & {$[6.0-8.0]$} & {$[4.3-8.0]$} & \\
\hline Maternal age (years) & & & & & & & 0.631 \\
\hline$<20$ & $7.5 \%$ & $5.7 \%$ & $8.4 \%$ & $9.1 \%$ & $7.1 \%$ & $8.8 \%$ & \\
\hline $20-24$ & $30.5 \%$ & $33.3 \%$ & $31.8 \%$ & $36.4 \%$ & $26.5 \%$ & $27.4 \%$ & \\
\hline $25-29$ & $33.0 \%$ & $32.6 \%$ & $35.5 \%$ & $20.5 \%$ & $30.1 \%$ & $38.9 \%$ & \\
\hline $30-34$ & $19.3 \%$ & $18.4 \%$ & $17.8 \%$ & $22.7 \%$ & $21.2 \%$ & $18.6 \%$ & \\
\hline $35+$ & $9.7 \%$ & $9.9 \%$ & $6.5 \%$ & $11.4 \%$ & $15.0 \%$ & $6.2 \%$ & \\
\hline mean $\pm \mathrm{SD}$ & $27.4 \pm 5.6$ & $27.5 \pm 5.6$ & $26.9 \pm 5.1$ & $26.8 \pm 6.0$ & $28.4 \pm 6.3$ & $26.8 \pm 5.3$ & 0.181 \\
\hline Educational level & & & & & & & $<0.001$ \\
\hline Not educated & $9.0 \%$ & $4.3 \%$ & $10.3 \%$ & $0.0 \%$ & $25.0 \%$ & $1.7 \%$ & \\
\hline Primary & $25.0 \%$ & $20.0 \%$ & $27.1 \%$ & $42.2 \%$ & $25.9 \%$ & $21.6 \%$ & \\
\hline Lower secundary & $38.5 \%$ & $42.1 \%$ & $40.2 \%$ & $33.3 \%$ & $34.8 \%$ & $37.9 \%$ & \\
\hline Higher secondary or more & $27.5 \%$ & $33.6 \%$ & $22.4 \%$ & $24.4 \%$ & $14.3 \%$ & $38.8 \%$ & \\
\hline Region of RGD clinic & & & & & & & 0.033 \\
\hline North-East & $33.7 \%$ & $36.2 \%$ & $24.3 \%$ & $48.9 \%$ & $37.2 \%$ & $30.2 \%$ & \\
\hline South-West & $66.3 \%$ & $63.8 \%$ & $75.7 \%$ & $51.1 \%$ & $62.8 \%$ & $69.8 \%$ & \\
\hline Infant gender & & & & & & & 0.907 \\
\hline Male & $49.6 \%$ & $46.8 \%$ & $52.3 \%$ & $51.1 \%$ & $51.3 \%$ & $48.3 \%$ & \\
\hline Female & $50.4 \%$ & $53.2 \%$ & $47.7 \%$ & $48.9 \%$ & $48.7 \%$ & $51.7 \%$ & \\
\hline Preterm birth & & & & & & & 0.365 \\
\hline Yes & $6.5 \%$ & $5.0 \%$ & $10.3 \%$ & $8.9 \%$ & $4.4 \%$ & $6.0 \%$ & \\
\hline No & $93.5 \%$ & $95.0 \%$ & $89.7 \%$ & $91.1 \%$ & $95.6 \%$ & $94.0 \%$ & \\
\hline Low birth weight & & & & & & & 0.067 \\
\hline Yes & $5.7 \%$ & $8.5 \%$ & $7.5 \%$ & $8.9 \%$ & $0.9 \%$ & $4.3 \%$ & \\
\hline No & $94.3 \%$ & $91.5 \%$ & $92.5 \%$ & $91.1 \%$ & $99.1 \%$ & $95.7 \%$ & \\
\hline
\end{tabular}

Because of rounding percentages do not always add up to $100 \%$

Significant $\mathrm{p}$-values are presented in bold 
Table 2: General characteristics of study population stratified for breastfeeding initiation $(n=522)$ and breastfeeding duration $(n=487)$

\begin{tabular}{|c|c|c|c|c|c|c|c|c|}
\hline \multirow[b]{3}{*}{ Maternal ethnicity } & \multicolumn{4}{|c|}{$\begin{array}{l}\text { breastfeeding initiation } \\
\qquad(\mathrm{n}=522)\end{array}$} & \multicolumn{4}{|c|}{$\begin{array}{c}\text { breastfeeding duration } \\
(\mathrm{n}=\mathbf{4 8 7})\end{array}$} \\
\hline & & $\begin{array}{c}\text { ever } \\
\text { breast } \\
\text { feeding }\end{array}$ & $\begin{array}{c}\text { never } \\
\text { breast } \\
\text { feeding }\end{array}$ & p-value & & $\begin{array}{c}<6 \\
\text { months }\end{array}$ & $\begin{array}{c}6+ \\
\text { months }\end{array}$ & p-value \\
\hline & $\mathrm{n}$ & $\%$ & $\%$ & 0.027 & $\mathbf{n}$ & $\%$ & $\%$ & $<0.001$ \\
\hline Creole & 141 & 91.5 & 8.5 & & 127 & 39.4 & 60.6 & \\
\hline Hindustani & 107 & 89.7 & 10.3 & & 96 & 72.9 & 27.1 & \\
\hline Javanese & 45 & 97.8 & 2.2 & & 44 & 50.0 & 50.0 & \\
\hline Mixed & 116 & 93.1 & 6.9 & & 108 & 26.9 & 73.1 & \\
\hline Maroon & 113 & 99.1 & 0.9 & & 112 & 23.2 & 76.8 & \\
\hline Maternal age & & & & & & & & 0.330 \\
\hline$<20$ & 39 & 89.7 & 10.3 & 0.524 & 35 & 54.3 & 45.7 & \\
\hline $20-24$ & 158 & 93.0 & 7.0 & & 146 & 41.8 & 58.2 & \\
\hline $25-29$ & 171 & 93.6 & 6.4 & & 160 & 35.6 & 64.4 & \\
\hline $30-34$ & 100 & 97.0 & 3.0 & & 96 & 40.6 & 59.4 & \\
\hline $35+$ & 50 & 92.0 & 8.0 & & 46 & 43.5 & 56.5 & \\
\hline Educational level & & & & 0.778 & & & & 0.660 \\
\hline Not educated & 47 & 95.7 & 4.3 & & 44 & 31.8 & 68.2 & \\
\hline Primary & 130 & 93.1 & 6.9 & & 121 & 41.3 & 58.7 & \\
\hline Lower secundary & 200 & 94.5 & 5.5 & & 188 & 42.0 & 58.0 & \\
\hline Higher secondary or more & 143 & 92.3 & 7.7 & & 132 & 40.4 & 59.8 & \\
\hline Region of RGD clinic & & & & 0.738 & & & & 0.066 \\
\hline North-East & 176 & 95.5 & 4.5 & & 167 & 46.1 & 53.9 & \\
\hline South-West & 346 & 92.8 & 7.2 & & 320 & 37.5 & 62.5 & \\
\hline Gender of infant & & & & 0.053 & & & & 0.348 \\
\hline Male & 259 & 95.8 & 4.2 & & 247 & 42.5 & 57.5 & \\
\hline Female & 263 & 91.6 & 8.4 & & 240 & 38.3 & 61.7 & \\
\hline Preterm birth & & & & 0.055 & & & & 0.621 \\
\hline Yes & 34 & 85.3 & 14.7 & & 29 & 44.8 & 55.2 & \\
\hline No & 488 & 94.3 & 5.7 & & 458 & 40.2 & 59.8 & \\
\hline Low birth weight & & & & 0.034 & & & & 0.227 \\
\hline Yes & 30 & 83.3 & 16.7 & & 25 & 52.0 & 48.0 & \\
\hline No & 492 & 94.3 & 5.7 & & 462 & 39.8 & 60.2 & \\
\hline
\end{tabular}

Significant p-values are presented in bold 
Table 3: Odds ratios (OR) with $95 \%$ confidence interval $(95 \% \mathrm{CI})$ for breastfeeding initiation $(\mathrm{n}=522)$ and breastfeeding duration $(\mathrm{n}=487)$

\begin{tabular}{|c|c|c|c|c|c|c|c|c|c|c|c|c|}
\hline & \multicolumn{6}{|c|}{$\begin{array}{l}\text { breastfeeding initiation } \\
\text { (never vs. ever) }\end{array}$} & \multicolumn{6}{|c|}{$\begin{array}{l}\text { breastfeeding duration } \\
\text { (<6 vs. } 6+\text { months) }\end{array}$} \\
\hline & \multirow{2}{*}{$\begin{array}{l}\text { crude } \\
\text { OR }\end{array}$} & \multicolumn{2}{|c|}{$95 \%$ CI } & \multirow{2}{*}{$\begin{array}{l}\text { adjusted } \\
\text { OR }\end{array}$} & \multicolumn{2}{|c|}{ 95\% CI } & \multirow{2}{*}{$\begin{array}{l}\text { crude } \\
\text { OR }\end{array}$} & \multicolumn{2}{|c|}{$95 \%$ CI } & \multirow{2}{*}{$\begin{array}{l}\text { adjusted } \\
\text { OR }\end{array}$} & \multicolumn{2}{|c|}{$95 \%$ CI } \\
\hline & & LB & UB & & LB & UB & & LB & UB & & LB & UB \\
\hline \multicolumn{13}{|l|}{ Maternal ethnicity } \\
\hline Creole & 10.4 & 1.3 & 81.4 & 9.3 & 1.2 & 73.5 & 2.1 & 1.2 & 3.8 & 2.2 & 1.2 & 3.8 \\
\hline Hindustani & 12.8 & 1.6 & 101.2 & 11.7 & 1.5 & 92.8 & 8.9 & 4.8 & 16.7 & 9.6 & 5.1 & 18.2 \\
\hline Javanese & 2.5 & 0.2 & 41.6 & 2.2 & 0.1 & 37.0 & 3.3 & 1.6 & 6.9 & 3.1 & 1.5 & 6.6 \\
\hline Mixed & 8.3 & 1.0 & 67.5 & 7.9 & 1.0 & 64.3 & 1.2 & 0.7 & 2.2 & 1.3 & 0.7 & 2.3 \\
\hline Maroon & 1.0 & & & 1.0 & & & 1.0 & & & 1.0 & & \\
\hline \multicolumn{13}{|l|}{ Maternal age } \\
\hline$<20$ & 1.0 & & & & & & 1.0 & & & & & \\
\hline $20-24$ & 0.7 & 0.2 & 2.2 & & & & 0.6 & 0.3 & 1.3 & & & \\
\hline $25-29$ & 0.6 & 0.2 & 2.0 & & & & 0.5 & 0.2 & 1.0 & & & \\
\hline $30-34$ & 0.3 & 0.6 & 1.3 & & & & 0.6 & 0.3 & 1.3 & & & \\
\hline $35+$ & 0.8 & 0.2 & 3.3 & & & & 0.6 & 0.3 & 1.6 & & & \\
\hline \multicolumn{13}{|l|}{ Educational level } \\
\hline Not educated & 1.0 & & & & & & 1.0 & & & & & \\
\hline Primary & 1.7 & 0.3 & 8.0 & & & & 1.5 & 0.7 & 3.1 & & & \\
\hline Lower secondary & 1.3 & 0.3 & 6.1 & & & & 1.6 & 0.8 & 3.1 & & & \\
\hline $\begin{array}{l}\text { Higher secondary } \\
\text { or more }\end{array}$ & 1.9 & 0.4 & 8.8 & & & & 1.4 & 0.7 & 3.0 & & & \\
\hline \multicolumn{13}{|l|}{$\begin{array}{l}\text { Region of } R G D \\
\text { clinic }\end{array}$} \\
\hline North-East & 1.0 & & & & & & 1.4 & 1.0 & 2.1 & 1.6 & 1.1 & 2.5 \\
\hline South-West & 1.6 & 0.7 & 3.7 & & & & 1.0 & & & 1.0 & & \\
\hline \multicolumn{13}{|l|}{ Infant gender } \\
\hline Male & 1.0 & & & & & & 1.2 & 0.8 & 1.7 & & & \\
\hline Female & 2.1 & 1.0 & 4.3 & & & & 1.0 & & & & & \\
\hline \multicolumn{13}{|l|}{ Preterm birth } \\
\hline Yes & 2.8 & 1.0 & 7.9 & & & & 1.2 & 0.6 & 2.6 & & & \\
\hline No & 1.0 & & & & & & 1.0 & & & & & \\
\hline \multicolumn{13}{|l|}{ Low birth weight } \\
\hline Yes & 3.3 & 1.2 & 9.3 & 2.7 & 1.0 & 7.9 & 1.6 & 0.7 & 3.7 & & & \\
\hline No & 1.0 & 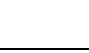 & 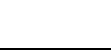 & 1.0 & 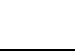 & 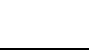 & 1.0 & 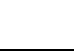 & & & & \\
\hline
\end{tabular}

